\title{
Adsorptive Removal of Methyl Red from Aqueous Solution using Charred and Xanthated Sal (Shorea robusta) Sawdust
}

\author{
Krishna Bahadur Dawadi, Mahesh Bhattarai ${ }^{1}$, Puspa Lal Homagai ${ }^{{ }^{*}}$ \\ ${ }^{1}$ Department of Chemistry, Amrit Campus, Thamel Kathmandu Nepal \\ *Email.homagaipl@gmail.com
}

(Received: 22 April, 2020, Received in revised form: 12 August, 2020, Accepted: 17 August, 2020, Available online)

\section{Highlights}

- Charred Sal Sawdust (CSSD) was prepared by acid treatment of raw Sal dust.

- Xanthated Sal Sawdust (XSSD) was prepared by treating CSSD.

- Methyl red was used as a model dye to study the adsorptive capacity of XSSD.

- Adsorption isotherms and kinetics has been studied.

- These adsorbents could be good alternatives for dyes removal.

\begin{abstract}
Adsorptive removal of methyl red (MR) from aqueous solution onto chemically modified Charred Sal (Shorea robusta) Saw-Dust (CSSD) and Xanthated Sal Saw-Dust (XSSD) has been investigated. The surface modification is characterized by Fourier transformed infra-red (FTIR) spectroscopy, scanning electron microscopy (SEM) and elemental Analysis. Different parameters are studied such as contact time, optimum $\mathrm{pH}$, and initial ion concentration. Maximum dye removal is observed at $\mathrm{pH} 4$ for charred and xanthated Sal saw dust. The dye can be quantitatively removed onto the surface of these adsorbent. At a contact time of 3-4 hours maximum adsorption capacity (qmax) for CSSD and XSSD are found to be $70 \mathrm{mg} / \mathrm{g}$ and $130 \mathrm{mg} / \mathrm{g}$ respectively. Adsorption kinetic data are best fitted onto pseudo second order. The obtained result indicated an excellent alternative for the treatment of dye contaminated waste water using such chemically modified Sal saw dust at low cost with better efficiency.
\end{abstract}

Keywords: Methyl Red, Charred Sal Sawdust, Xanthated Sal Sawdust, Adsorption - isotherms.

\section{Introduction}

Dye is a natural or synthetic colored compound which capacitates to bond chemically with the substrate being applied to it. Dye constitutes a large group of industrial chemicals with over 700,000 tons of waste produced annually (Itodo, Usman \& Ugboaja, 2011). The colorants obtained from plants, minerals or any naturally occurring substances are called natural dyes. Highest percentage of naturally occurring dyes is obtained from plant sources like roots, leaves, bark and wood of trees. Increased demand for readily available, inexpensive, and easily applicable dyes led to the invention and rapid growth of synthetic dyes (Laxmi, 2014).

Synthetic dyes are being popularly used for different purposes in printing, paper, textile industry and pulp manufacturing (Venkata et al, 2017). Dyes are used in large quantities in many industries including textile, leather, cosmetics, paper, printing, plastics, pharmaceuticals, food, etc. to color their products, which generates waste water, characteristically high in color and

${ }^{*}$ Corresponding author 
organic content. The textile industry alone accounts for two third of the total dye stuff effluent (Azhar et al, 2005). Environmental pollution due to industrial effluents is the major concern because of their toxicity and threats for human life and the environment (Amren and Zulfikar, 2010). These industrial discharges are highly colored with high biochemical oxygen demand (BOD) as well as chemical oxygen demand (Lee, Low \& Gan, 1999).

Methyl red (MR) is an azo dye having chemical formula $\mathrm{C}_{15} \mathrm{H}_{15} \mathrm{~N}_{3} \mathrm{O}_{2}$ with molecular weight $269.31 \mathrm{~g} / \mathrm{mole}$ and melting point in the range of $179-182^{\circ} \mathrm{C}$ (Hassan \& Abdulhussein, 2015). It is a pH indicator; it is yellowish in $\mathrm{pH}$ more than 6.2, red in $\mathrm{pH}$ values under 4.4 and orange in between. It was selected as a model dye due to its intense colour in aqueous systems and low biodegradability because of the benzene rings. It is a toxic compound which may cause carcinogenesis, mutagenesis, teratogenesis and respiratory toxicity (Laxmi, 2014). This not solely avoids sunrays penetration into water and decreases photosynthetic activity but also results in causing difficulties within the atmosphere (Yaoji et al, 2018). MR has been used to treat Saprolegenia and used as an antibacterial chemical substance (Ferdous et al, 2014). It can cause irritation in humans and animals, such as methemoglobinemia, cyanosis and convulsions, irritation of the eye, skin and digestive tract if inhaled or swallowed (Venkata et al, 2017).

Over the past few decades, conventional waste water treatment methods for removing dyes include biological (aerobic and anaerobic), chemical and physiochemical methods such as coagulation and flocculation, solvent extraction, membrane filtration, ozonation, ion exchange, electrochemical techniques, fungal decolonization and adsorption (Enenebeaku and ilkechukwu, 2017). Possible methods of dye removal from textile effluents include chemical oxidation, forth flotation, adsorption, coagulation, electro-dialysis, cloud point extraction, etc. (Abdulaziz et al, 2019; Santhi, 2010). Activated carbon is one of the popular adsorbent because of its high effective surface area, high adsorption capacity, high degree of surface reactivity, and low cost of treatment process. Therefore, scientists are working to investigate the inexpensive and efficient adsorbent materials (Dhimiral, 2008; Hassan, 2015).

These adsorbents are abundantly available, economical, eco-friendly, renewable, cheaper, with excellent dye removal capacity. For these reasons, many researchers have tried to prepare activated carbons from agricultural wastes, such as banana peels, plum kernels, oil palm shells, tealeaves, sawdust, wheat bran, coffee grounds, coconut husk, jackfruit peel and rice husks (Gupta, 2009; Ayyappan et al, 2005). Normally, colorants are dispersible or water soluble organic compounds capable of being absorbed in to the substrate destroying the crystal structures of the substrate (Chatterjee, Lee and Woo, 2009\&2010).

Sal sawdust is carbon rich, well known bio-adsorbent whose constituent may be cellulose, pectin, lignin, and the functional group such as $-\mathrm{COOH},-\mathrm{NH},-\mathrm{CHO}$, etc. These negatively charged functional groups in adsorbents attracts positively charged ions in a dye, hence adsorption takes place. Bio-adsorbents, charred as well as its modified state is used to enhance removal of MR from aqueous solution (Koninika, 2015). Such bioadsorbent can be modified by chemical treatment to enhance its high surface area onto the product. At this present situation of industrialization, rapid population growth and urbanization, the water resources are getting polluted day by day due to the disposal of wastewater containing dye and heavy metal ions. To prevent the contamination of such industrial waste before its disposal to the land or source of water it must be purified. So, adsorption may be one of the best remedy for the purification. In search of new adsorbent, chemically modified Sal sawdust could be used and its efficiency is evaluated for the removal of MR dye. Under such circumstances, we have explored a process of chemical modification which revealed to have better adsorption properties with the inclusion of amine functional group onto the surface of the adsorbent.

\section{Materials and Methods}

\section{Materials}

Sulphuric acid, methyl red (purity 99.5\%), sodium hydroxide, were purchased from Thermofiscer Scientific Pvt. Ltd., India. All the reagents were of analytical grade and used as received without any further purification.

\section{Preparation of adsorbent from raw Sal Sawdust}

Raw Sal sawdust was collected from the local sawmill situated at Chitwan Bharatpur. It was then sun dried for 2-3 days to remove moisture from the sawdust. After complete dry, it was taken for the further process in laboratory and thus adsorbent was prepared. 


\section{Preparation of Charred Sal sawdust adsorbents (CSSD)}

$500 \mathrm{~g}$ of raw Sal sawdust was taken in a bucket and conc. $\mathrm{H}_{2} \mathrm{SO}_{4}$ was added and stirred it with wooden spatula until it turns to complete black color. Then it was left for 24 hours with occasional stirring with wooden spatula and thus complete reaction took place. The process is hence called the charring process. In this charring process ring opening of cellulose takes place. The charcoal formed was soaked in rain water for more 24 hours. Again the charcoal was washed several times with rainwater. Further, sample was washed with distilled water and the sample was completely neutralized up to $\mathrm{pH} 7$ and was kept for shade dry. After 2-3 days of shade dry it was dried in an oven for 6 hours. The dried charcoal was grinded and sieved with $250 \mu \mathrm{m}$ and $150 \mu \mathrm{m}$. Finally, the charred sample of sawdust got ready and was kept in air tight bottle.

\section{Preparation of Xanthated Sal sawdust (XSSD)}

$100 \mathrm{~g}$ of the charred saw dust was taken in a reagent bottle, $100 \mathrm{~mL}$ of $1 \mathrm{~N} \mathrm{NaOH}$ was added in it and shaken in to a mechanical shaker for 4 hours and the $20 \mathrm{~mL}$ of carbon disulphide was added in it and again shaken into mechanical shaker for 6 hours and left overnight and the process is known as xanthation. The solution was then filtered into Whatman filter paper. Charcoal obtained was then washed with rain water and then deionized water for making the sample neutral. Thus obtained charcoal was then shade dried for 3 days and oven dried for 6 hours for complete removal of moisture from the charcoal and at the end, $80 \mathrm{~g}$ product was obtained. Xanthate saw dust was taken in desiccator for1 hour and stored clean bottle.

\section{Chemicals}

Stock solution of MR dye was prepared by dissolving $1 \mathrm{~g}$ of MR dye in 1000 $\mathrm{mL}$ adding ethanol to give $1000 \mathrm{ppm}$ solution. Other working solutions of MR dye were prepared by diluting the stock solution in distilled water.

\section{Instrumentation}

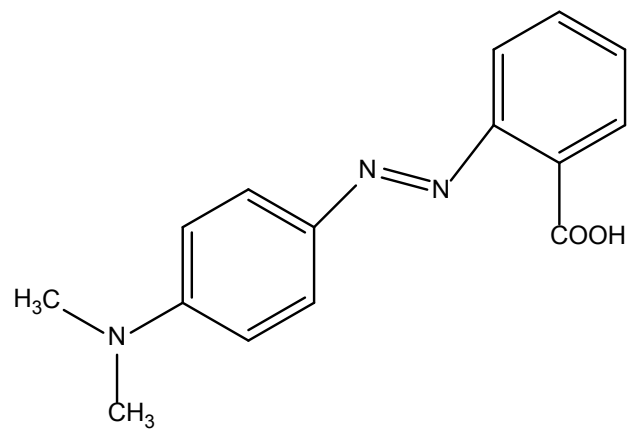

Fig 1: Molecular structure of MethylRed

Calibration curve of Methyl Red was constructed using UV spectrophotometer (Labtronics, LT-2802) at maximum wave length of $620 \mathrm{~nm}$ at $\mathrm{pH}$ 4. Similarly, $\mathrm{pH}$ of the solution was monitored using $\mathrm{pH}$ meter (Digital $\mathrm{pH}$ meter, Labtronics-11, India). SEM images of samples were taken to investigate the surface morphology of the activated carbons using FE-SEM, HITACHI, SUB8230, Tokyo, Japan). FTIR (SHIMADZU, IRPrestige-21) spectrum of Sal saw dust, CSSD and XSSD before and after adsorption of MR dye were analyzed.

\section{Experimental procedure}

Batch adsorption experiment was carried out in a mechanical shaker maintaining temperature of $25^{\circ} \mathrm{C} .25 \mathrm{~mL}$ of Methyl red solution of known concentration was shaken at constant agitation speed (150rpm) with constant adsorbent dose $25 \mathrm{mg}$ for specific period of time about 24 hours in mechanical shaker. The $\mathrm{pH}$ of the solution was adjusted by using dilute $\mathrm{HCl}$ and $\mathrm{NaOH}$ solution. After equilibrium, the final concentration (ce) were measured and the amount of methyl red adsorbed in $\mathrm{mg} / \mathrm{g}$ at equilibrium was computed by the equation

$$
q=\frac{c_{i}-c_{e}}{w} \times V
$$

$c_{i}$ and $c_{e}$ are the initial concentration of dye solution and equilibrium concentration of metal ion in $\mathrm{mg} / \mathrm{L}, \mathrm{V}$ is volume of Methyl red in Liter.

The removal percentage is calculated using the following relation

$$
\% A=\frac{C_{i}-C_{e}}{C_{t}} \times 100
$$

Where $\% \mathrm{~A}$ is the Percentage of Dye adsorption from the solution. 


\section{Results and Discussion}

\section{Characterization of adsorbent}

\section{SEM image of adsorbent}

The SEM image of RSSD, CSSD (Before and after) and XSSD (before and after) are shown in figure 2A, 2B, 2C, 2D and $2 \mathrm{E}$ respectively. SEM observations of CSSD revealed its non-uniform and rough surface that changed into irregular honeycomb structure of XSSD. The XSSD showed apparently isolated and irregularly distributed pores, which are supposed to be formed due to the increase in effective diffusion surface area that helps to expose more surface-active binding sites and finally enhance adsorption capacity of the modified Sal sawdust. Similarly, the CSSD (ads) and XSSD (ads) showed that after the adsorption of dye, the honeycomb surface like structure is completely filled which indicates that the adsorption has taken place properly.
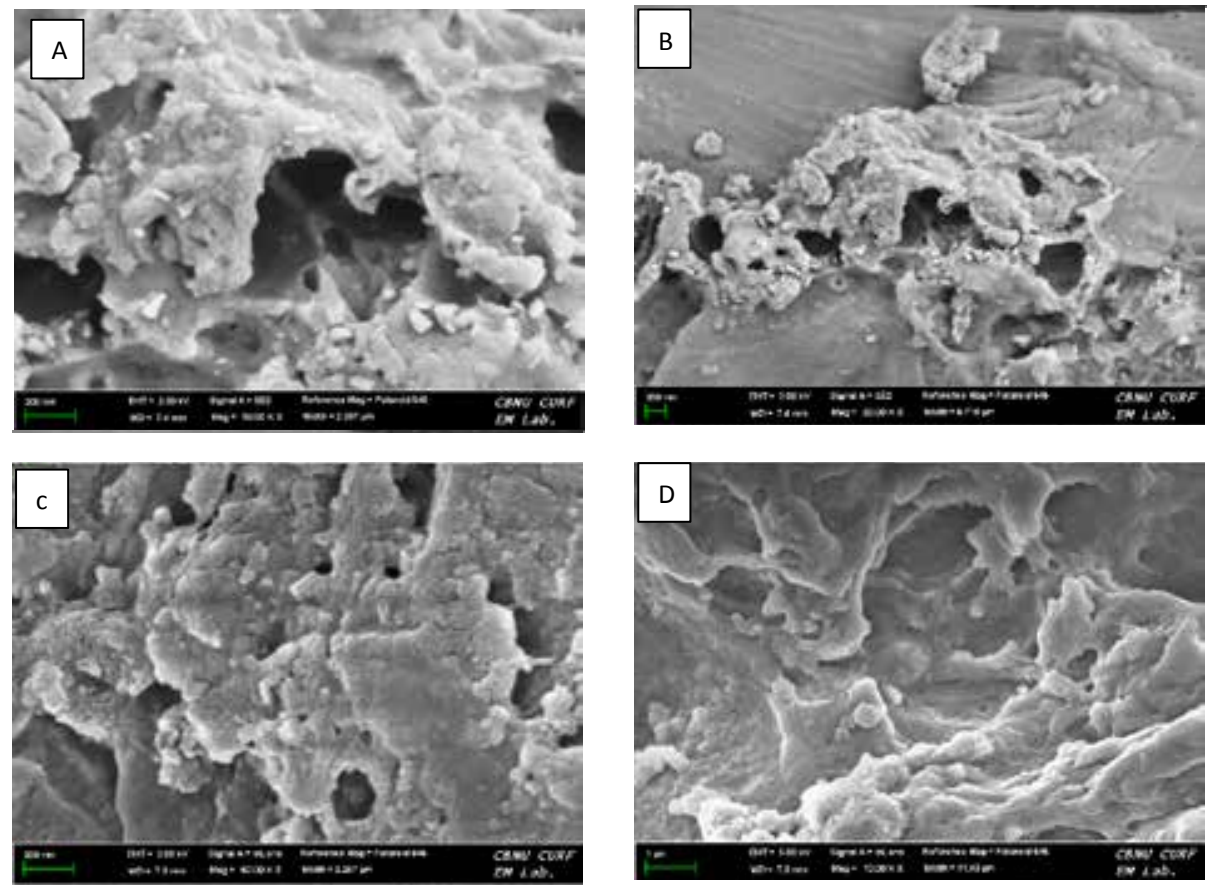

Fig 2: SEM image of A. RSSD, B. CSSD before, C. CSSD after, D. XSSD before, E. XSSD after adsorption

\section{Infrared spectra analysis}

The combined FTIR spectrum of RSSD and CSSD, CSSD (ads) and XSSD (ads), are shown in the following figure separately. The FTIR spectrums of adsorbents were taken between $400-3500 \mathrm{~cm}^{-1}$ using IR tracer. By the close inspection of FTIR spectrum the samples showed clear and broad centered at 3200-3600 which is because of vibrations of -OH groups of alcohols, Phenols or Carboxylic acids. The band is very intense in RAW and decreased on modified samples. This means the moisture content after treatment drastically decreased hence, the amount of carbon remains in the sample. The broad peak observed at 3317.27 are due to the existence of bounded hydroxyl groups. The peak observed at 2916.37 can be assigned to C-H group. The peak around 1026.13 (RSSD), 1018.41 (CSSD), 1018.41 (CSSD ads), 1018.41 (XSSD), 1018.41(XSSD ads) are the characteristics of C-O group of primary hydroxyl group also the peaks at 1597.06(RSSD), 1597.06 (CSSD), 1597.06 (CSSD ads), shows N-H group present at all adsorbent. The

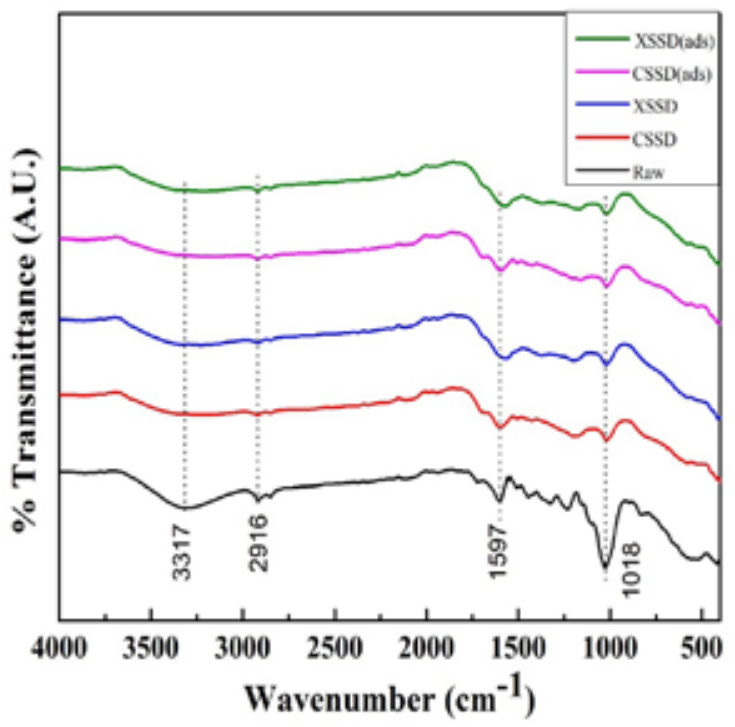

Fig 3: FTIR spectrum of Raw, CSSD, CSSD (ads) XSSD and XSSD (ads 
sulfate is found between the range of 1380-1415 and the result extracted is found that band 1157.29 at CSSD is depicted to 1373.03 revealing that sulphate group has been introduced on CSSD. The result from the graph shows that XSSD which contains Sulphur group has been more effective for the removal of MR dye in comparison with CSSD as bioadsorbent.

\section{Effect of $\mathrm{pH}$}

The $\mathrm{pH}$ of the solution has a significant impact on the uptake of MR dye, since it determines the surface charge of the adsorbent and the degree of ionization of the adsorbate. The effect of $\mathrm{pH}$ on adsorption MR was presented in Figure 4. At low $\mathrm{pH}$ there is high concentration of $\mathrm{H}^{+}$ion which may cause the low adsorption of methyl Red cation but at high $\mathrm{pH}$ there is high adsorption of MR due to low $\mathrm{H}^{+}$concentration.

From the $\mathrm{pH}$ studies, the optimum $\mathrm{pH}$ for both CSSD and XSSD was found to be 4.0. It can also be noted from the above figure that percentage removal for XSSD is found to be effective than that of CSSD i.e., $86.63 \%$ and $62.63 \% \%$ respectively. It was confirmed by the observation that the sharp increase in final $\mathrm{pH}$ of the solution at optimum $\mathrm{pH}$ at which maximum adsorption of dye had taken place.

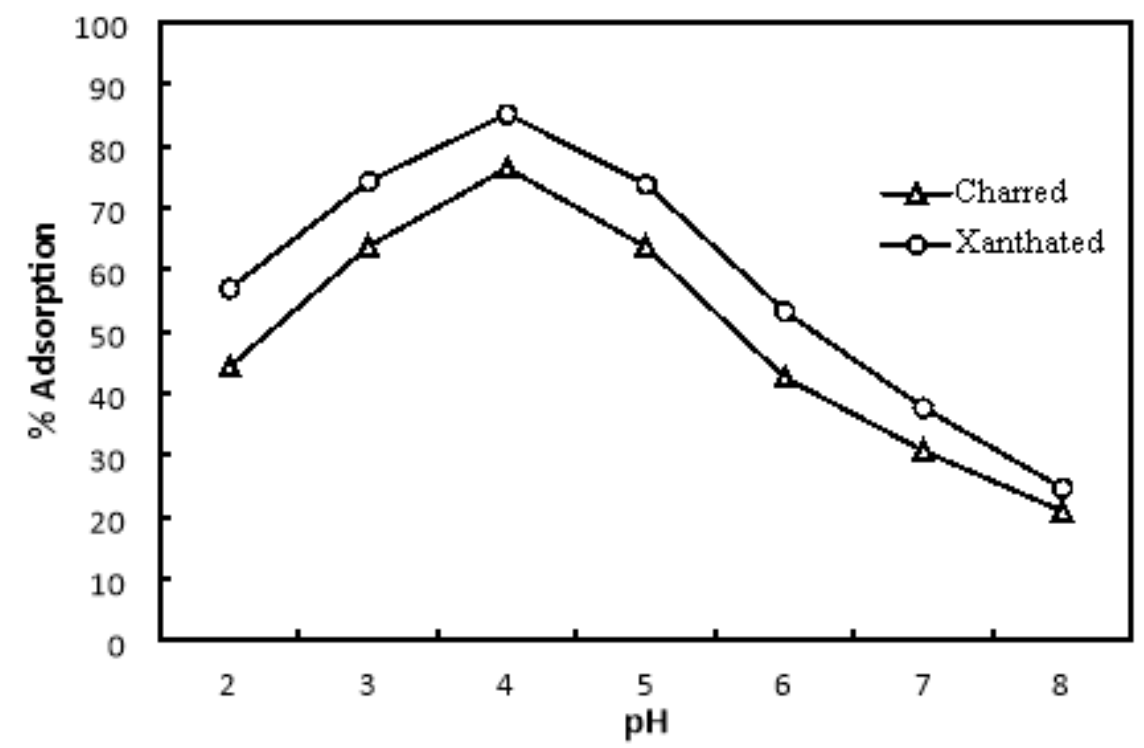

Fig 4: Adsorption of methyl red on CSSD and XSSD as function of $p H$

\section{Investigation of sorption parameter}

\section{Adsorption kinetic studies}

Kinetic study for the adsorption of MR onto CSSD and XSSD were studied using Pseudo second Order Model. Different parameters were calculated from the Kinetic plots for the adsorption of Methyl Red onto CSSD and XSSD. The Pseudo-Second Order Kinetics model is given by

$$
\frac{t}{q_{t}}=\frac{1}{K_{2} q_{e}^{2}}+\frac{t}{q_{e}}
$$

Where $\mathrm{K}_{2}$ is the rate constant for Pseudo second order adsorption in (g/mg.min), $\mathrm{q}_{2}$ and $\mathrm{q}_{\mathrm{e}}$ are the amount of MR adsorbed $(\mathrm{mg} / \mathrm{g})$ at any time and equilibrium time respectively. It was observed from the experimental data that the correlation coefficient $\left(\mathrm{R}^{2}\right)$ for pseudo second order was found to be closed to unity for all case which indicates that pseudo second order model is best fitted. If the initial adsorption rate is $\mathrm{V}_{0}(\mathrm{mg} / \mathrm{g}$ min $)$ then

$$
\mathrm{V}_{0}=K_{2} q_{e}^{2}
$$

The equation (3) can also be written as,

$$
\frac{\mathrm{t}}{\mathrm{q}_{\mathrm{t}}}=\frac{1}{\mathrm{~V}_{0}}+\frac{\mathrm{t}}{\mathrm{q}_{\mathrm{e}}}
$$


Experimentally the value of $\mathrm{q}_{e}$ and $\mathrm{K}_{2}$ can be determined from the linear plot of $t / \mathrm{q}_{t}$ vs $t$ with the help of slope and intercepts as shown in figure.

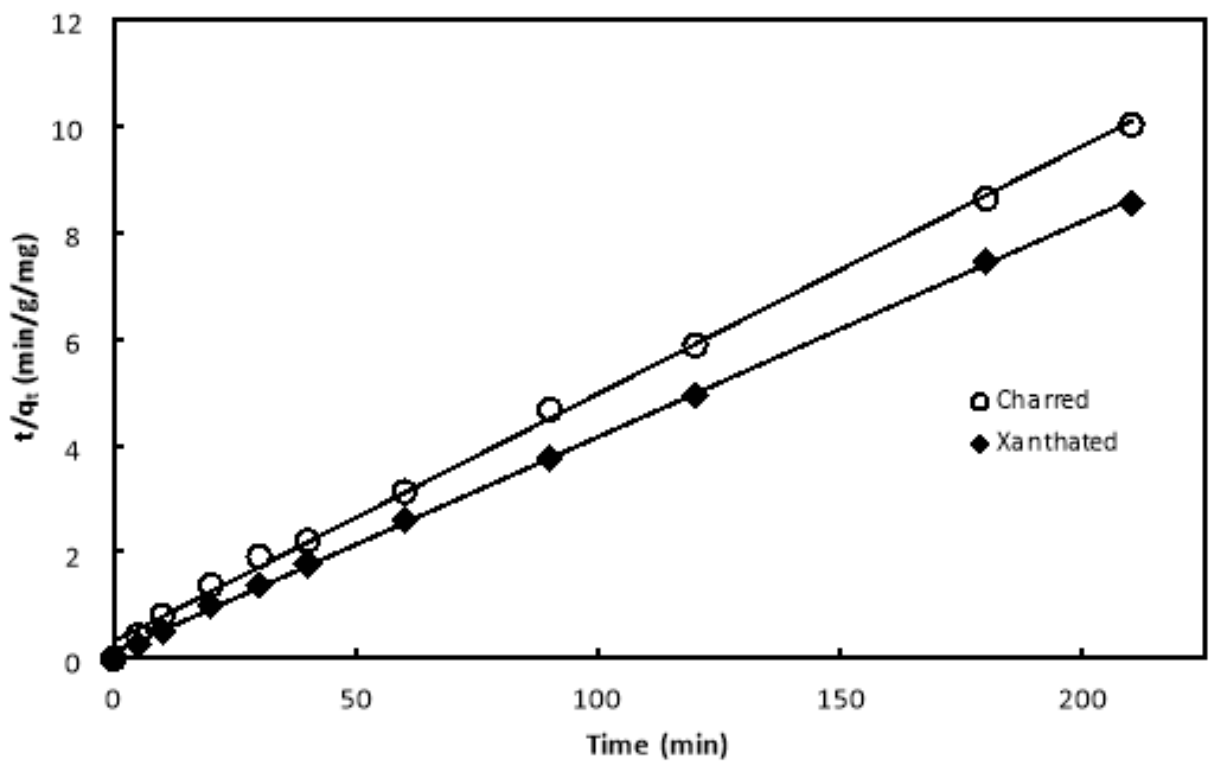

Fig 5: Pseudo-second order kinetic model for adsorption of MR dye onto XSSD andCSSD.

\section{Adsorption isotherm studies}

The Langmuir isotherm was studied by adsorption experiment as a function of methyl red concentration in aqueous solution at equilibrium time and optimum $\mathrm{pH}$ condition and plots are shown in figure 6.

$$
\frac{C_{e}}{q_{e}}=\frac{1}{q M_{b}}+\frac{C_{e}}{q_{m}}
$$

Where, $\mathrm{q}_{\mathrm{e}}$ is milligram of metal per gram of adsorbent at equilibrium $(\mathrm{mg} / \mathrm{g}), \mathrm{C}_{\mathrm{e}}$ is equilibrium concentration of adsorbate $(\mathrm{mg} / \mathrm{L}), \mathrm{q}_{\mathrm{m}}$ is maximum adsorption capacity $(\mathrm{mg} / \mathrm{g})$ and $\mathrm{b}$ is the Langmuir adsorption equilibrium constant $(\mathrm{L} / \mathrm{mg})$. The sorption capacity will increase with increase in initial concentration gradient. At lower initial concentration sufficient sorption sites are available for the sorption of the metal ions therefore the fractional sorption is independent of initial dye ion concentration. Therefore, at higher initial concentration, the numbers of dye ions are relatively higher than adsorption sites; hence the removal percentage depends on the initial concentration. The Langmuir isotherm parameter qmax indicate maximum adsorption capacity of adsorbents. Due to the high value of qmax these two adsorbents would be an alternative to activated carbon for the adsorption of dyes. The result extracted showed that effective adsorption is done at XSSD rather than CSSD Its optimum $\mathrm{pH}$ is 4 . Figure 6 shows the Langmuir plot for adsorption of MR dye onto CSSD and XSSD. The high value of Langmuir correlation coefficient confirmed that the Langmuir model is best fitted.

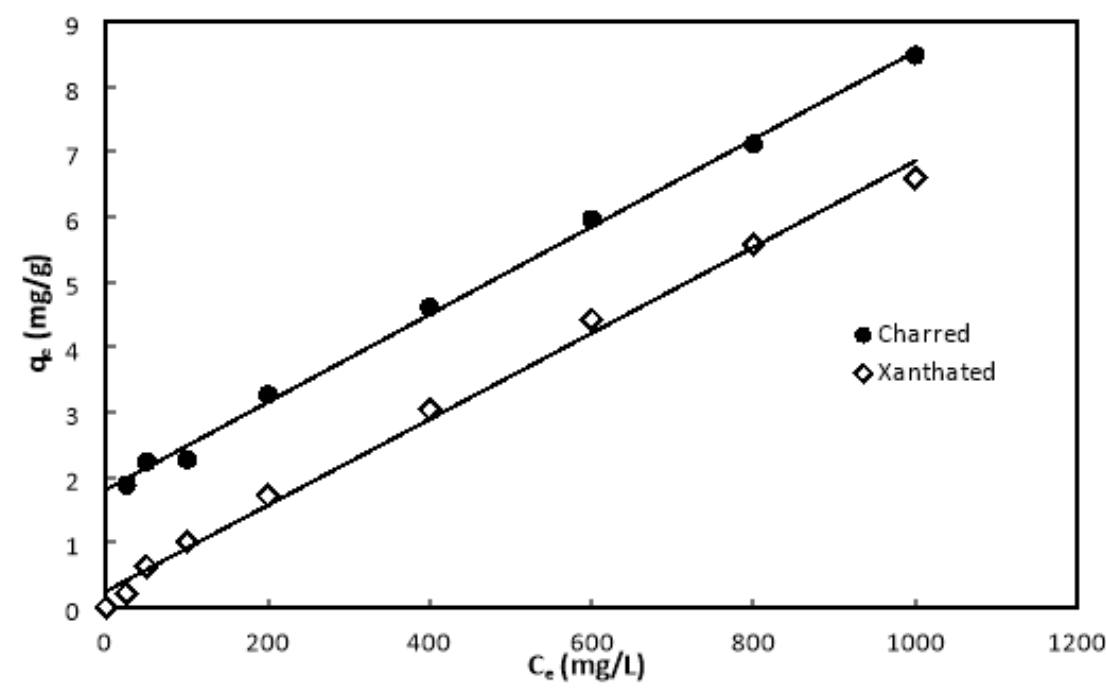

Fig 6: Langmuir plot for adsorption of MR dye onto CSSD and XSSD 
Table1: comparison of maximum adsorption capacity $\left(q_{\max }\right)$ between earlier and present studied Bio-adsorbent

\begin{tabular}{|l|c|l|}
\hline \multicolumn{1}{|c|}{ Bio adsorbents } & $\begin{array}{c}\text { q } \\
\text { of } \text { max }_{\text {MR adsorption }}\end{array}$ & \multicolumn{1}{c|}{ Sources } \\
\hline Annona squmosa seed & 90.6 & Santhi et al., (2010) \\
\hline Granular Cucumis sativa & 120.0 & Smitha et al., (2009) \\
\hline Banana pseudo fibre & 88.5 & Rosemalet al., (2009) \\
\hline Formaldehyde treated sugarcane bagasses & 88.8 & Azahar et al., (2005) \\
\hline Sulphuric acid treated sugarcane bagasses & 94.55 & Azahar et al., (2005) \\
\hline Charred sugarcane bagasses & 125.0 & Kour et al.,(2013) \\
\hline Aminated sugarcane bagasse & 142.85 & Kour et al.,(2013) \\
\hline Charred Sal saw dust & 70.0 & [present study] \\
\hline Xanthated Sal saw dust & 130.0 & [present study] \\
\hline
\end{tabular}

\section{Conclusions}

With the help of simple chemical modification of Sal Sawdust, it has been found that it is efficient for the removal of MR dye from aqueous solution. The adsorption experiments done in our research laboratory indicated that for both adsorbents - CSSD and XSSD- are among the few of the good adsorbents which were previously researched. Thus, it is concluded that CSSD and XSSD good adsorbents for the removal of MR dye. The obtained equilibrium adsorption data were best fitted to Langmuir isotherm with higher correlation coefficient for XSSD and CSSD respectively. Similarly, from adsorption kinetics study it is concluded that CSSD and XSSD follows Pseudo-second order kinetics which is also verified by higher correlation coefficient for XSSD and CSSD respectively. Hence, it is concluded that XSSD and CSSD can be used for the removal of MR dye from aqueous solution. Furthermore, the result showed that XSSD may be an attractive alternative for the removal of MR dye from aqueous solution in comparison to CSSD as bio-adsorbent.

\section{Acknowledgements}

Authors would like to thank Asst. Prof. Kamal Sapkota for FE-SEM analysis and Department of Plant Resources, Thapathali, Kathmandu for FTIR spectra. Also thankful to Department of Chemistry, Amrit Campus, Tribhuvan University, Thamel, Nepal, for providing necessary physical facilities.

\section{References}

Abdulaziz, A.A., Abdel-Basit A.O. and Waseem, S.S. 2019. Adsorption of Azo Dye Methyl Orange from Aqueous Solutions Using Alkali-Activated Polypyrrole- Based Graphene Oxide, Molecules, 24:3685.

Amren, M.B. \& Zulfikar, M.A. 2010. Removal of Malachite green dye by adsorption onto phyrophyllite. International journal of environmental studies, 67(6):911- 921

Ayyappan, R., Sophia, C. A., Swaminanthan, K. \& Sandhya, S. 2005. Removal of Pb (II) from aqueous Solution Using Carbon Derived from Agricultural Wastes. Process Biochemistry, 40(40): 1293-1299

Azhar, S.S., Liew, A.G., Sauhardy, D., Hafiz, K.F., Hatim, M.D.I., 2005. Dye removal from aqueous solution by using adsorption on treated sugarcane bagasse. Journal of applied Science, 2(11):1499.

Chatterjee, S., Lee, M.W. \& Woo, S.H. 2009. Adsorption of malachite green from aqueous solution using chitosan hydrogel beads formed by various anionic surfactant, Journal of Chemical Pharmacological Research. 98, 1000-1200. 
Chatterjee, S., Lee, M.W. \& Woo, S.H. 2010. Adsorption of malachite green chitosan hydrogen beads impregnated with carbon nanotubes, Bioresource Technology, 101:1800-1806.

Dimiral, H. \& Dimiral, I. 2008. Surface Properties of Activated Carbon Prepared from Wastes. Surface Interface and analysis, 40(3-4):612-615.

Enenebeaku E.U. and ilkechukwu C.U. 2017. Adsorption and Equilibrium Studies on the Removal of Methyl Red from Aqueous Solution Using White Potato Peel Powder. International Letters of Chemistry, Physics and Astronomy. 72:52-64.

Ferdous, J. Zainal-Abedin, Hafizur-Rahman and M-Ali-Hossain. 2014. Decolorization of Methyl Red by Hog Plum Peel and Sunfix Red by Bacterial Strains. International Journal of Chemical and Environmental Engineering. 5(1):66-68.

Gupta, V.K. 2009. Application of Low- cost Adsorbents for Dye Removal-a Review, Journal of Environmental Management, 90(8):2313-2342.

Hassan, A.A and Abdulhussein, H. 2015. Methyl Red Dye Removal From Aqueous Solution by Adsorption on Rice Hulls. Journal of Babylon University, 3: 23

Hassan, A.A. and Hadeel Ali Abdulhussein. 2015. Methyl Red Dye Removal from Aqueous Solution by Adsorption on Rice Hulls. Journal of Babylon University, 23(2).

Itodo, U., Usman.A. and Ugboaja.C. 2011. A Rate Study of Received and Derived Activated Carbon and Pseudo Constants for Methyl Red Sorption. Journal of Encapsulation and Adsorption Sciences, 1:57- 64.

Koninika, T. and Zainal. M.A. 2015. A Novel Bio adsorbent for the Removal of Methyl Red from Aqueous Solutions. IOSR Journal of Environmental Science, Toxicology and Food Technology, 9:87-91.

Kour. J., Pandey, S., Homagai, P.L., Pokhrel M. R.\& Ghimire K.N. 2013. Adsorptive removal of MR from aqueous solution onto charred and aminated sugarcane waste. Journal of membrane and separation technology, 2:63-73.

Laxmi, V. 2014. Removal of malachite green dye from water using orange peel as an adsorbent. Master of Technology Dissertation, National Institute of Technology, India.

Lee, C.K., Low, K.S.\& Gan, P.Y. 1999. Removal of some organic dyes by acid treat spent bleaching earth. Environmental Technology, 20:99-104.

Santhi. T, Manonmaniand, S, and Smitha.T. 2010. Removal of methyl red from aqueous solution onto activated carbon prepared from the Annona squomosa seed by adsorption. Chemical Engineering Research Bulletin 14:11-18.

Venkata, K.R., Swarna, L., Rabindranath, K., and Rasayan, H. B. 2017. Adsorptive removal of methyl red using New adsorbent Hyacinth and Antinospora Cordofolia plant from waste water. Journal of Chemistry, 10(2):349 -362.

Yaoji T., Rui Y., Dong M.A., Bin Z.L.,and Jing.Y. 2018. Removal of Methyl Orange from Aqueous Solution by Adsorption onto a Hydrogel Composite. Polymer \& Polymer Composites, 26(2):161-168 